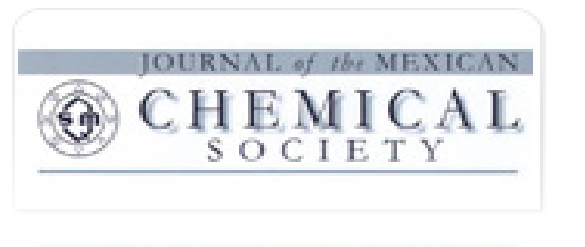

Journal of the Mexican Chemical Society

ISSN: 1870-249X

editor.jmcs@gmail.com

Sociedad Química de México

México

Garritz, Andoni

Francisco Giral González: un verdadero maestro

Journal of the Mexican Chemical Society, vol. 46, núm. 2, abril-junio, 2002, pp. 193-195

Sociedad Química de México

Distrito Federal, México

Disponible en: http://www.redalyc.org/articulo.oa?id=47546220

Cómo citar el artículo

- Número completo

- Más información del artículo

Página de la revista en redalyc.org

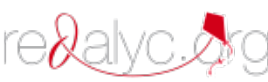

Sistema de Información Científica

Red de Revistas Científicas de América Latina, el Caribe, España y Portugal

Proyecto académico sin fines de lucro, desarrollado bajo la iniciativa de acceso abierto 


\title{
Obituario
}

\section{Francisco Giral González: un verdadero maestro}

\author{
Andoni Garritz \\ Facultad de Química de la Universidad Nacional Autónoma de México. Ciudad Universitaria, Circuito Escolar. México 04510,
} D.F. Tel.: (55) 5622-3439

El pasado mes de enero perdimos a un verdadero maestro. Falleció Francisco Giral González, alguien a quien, ya lo creo, mucho nos esforzaremos por emular, pero nunca lograremos sustituir. Dice Jaime Kravzov [1] que poseía don Francisco "esa cualidad que es síntesis de generosidad, sabiduría y amplitud de criterio, capaz de contagiar en quienes le rodean la pasión por el conocimiento, que hace que esos otros se interesen por el camino del saber, dándole continuidad a su búsqueda de una aplicación más humana de la ciencia”. Nada, un verdadero maestro.

Recuerdo cuando don Francisco nos decía, una y mil veces, que Alfonso X, nuestro rey sabio, hizo la primera y mejor definición de lo que debe ser una Universidad como «...ayuntamiento de maestros y escolares... hecho con voluntad y con entendimiento de aprender los saberes», sólo que, añadía el doctor Giral, desde la plataforma de las ciencias experimentales modernas, yo le agregaría los haceres a los saberes, o dejaría bien claro que el «saber» incluye el «saber hacer». Así, en pocas palabras, nunca perdonó a Alfonso X el Sabio no haber hecho explícito que la Universidad pretende el aprendizaje de los haceres y los saberes, ambos al mismo tiempo, ambos iguales en importancia, ambos indispensables. Estaba de acuerdo con Bernardo Houssay, premio Nobel argentino por sus logros en la experimentación fisiológica y bioquímica, cuando decía: «el desprecio al trabajo manual es una tradición que nos viene desde la época colonial».

Decía don Paco — como amablemente nos permitía a los jóvenes dirigirnos a él— "No se puede hacer ciencia experimental, y muy particularmente, no se puede hacer química, sin una buena dosis de trabajo manual, de esos «haceres» que omitió la definición de Las Partidas. Como químico experimental, puedo proclamar muy alto el inmenso placer que he sentido siempre que he tenido que realizar una muy buena experimentación, al comprobar la suprema actividad humana que significa realizar algo nuevo con las manos dirigidas por la propia mente" [2].
El doctor Giral vio nacer su interés científico en las reboticas familiares, primero con el recuerdo de su abuelo, Francisco González Serrano, y posteriormente con el ejemplo de su padre, José Giral Pereira, a quien considera como «su maestro de la vida, maestro de vocación y maestro de profesión», ambos fundamentales en su desarrollo personal y en su irrenunciable propósito de considerar a la farmacia, sobre todo, como un servicio sanitario, y un apoyo sustancial para el quehacer de la medicina.

Además de los ejemplos familiares, el perfil científico del doctor Giral se delineó gracias a maestros como don Miguel Catalán, quien en el bachillerato lo inició en la química y la física; don Enrique Moles, profesor de Química Inorgánica, y don Antonio Madinaveitia, director de su tesis profesional y posteriormente Director fundador del Instituto de Química en 1941, en México, donde ambos lograron sus aspiraciones de vivir en la libertad y en el ambiente propicio para sus investigaciones.

Obtuvo los doctorados en Farmacia y en Ciencias Químicas por la Universidad Central de Madrid, en la que su padre llegó a fungir como Rector. Completó su formación científica durante un posgrado que cursó en Heidelberg, Alemania. Allí llegó por consejo del célebre maestro Richard Willstäter, Premio Nobel de química en 1913, quien lo había recomendado con su más joven discípulo, Richard Kuhn, premio Nobel posteriormente en 1939. Con Kuhn publicó varios trabajos, de 1933 a 1935, en revistas científicas alemanas y españolas. Esta etapa de su vida académica fue sin lugar a dudas decisiva para su carrera como investigador.

En febrero de 1936 ganó por oposición la cátedra de química orgánica aplicada a la farmacia de la Universidad de Santiago de Compostela. Debido a su clara filiación republicana, fue destituido por razones políticas en noviembre de ese mismo año por la Junta de Burgos. Se desempeñó en diversas actividades químico industriales al servicio del gobierno de la República Española y tras la derrota de éste por las fuerzas falangistas, fue internado en un campo de concentración en 


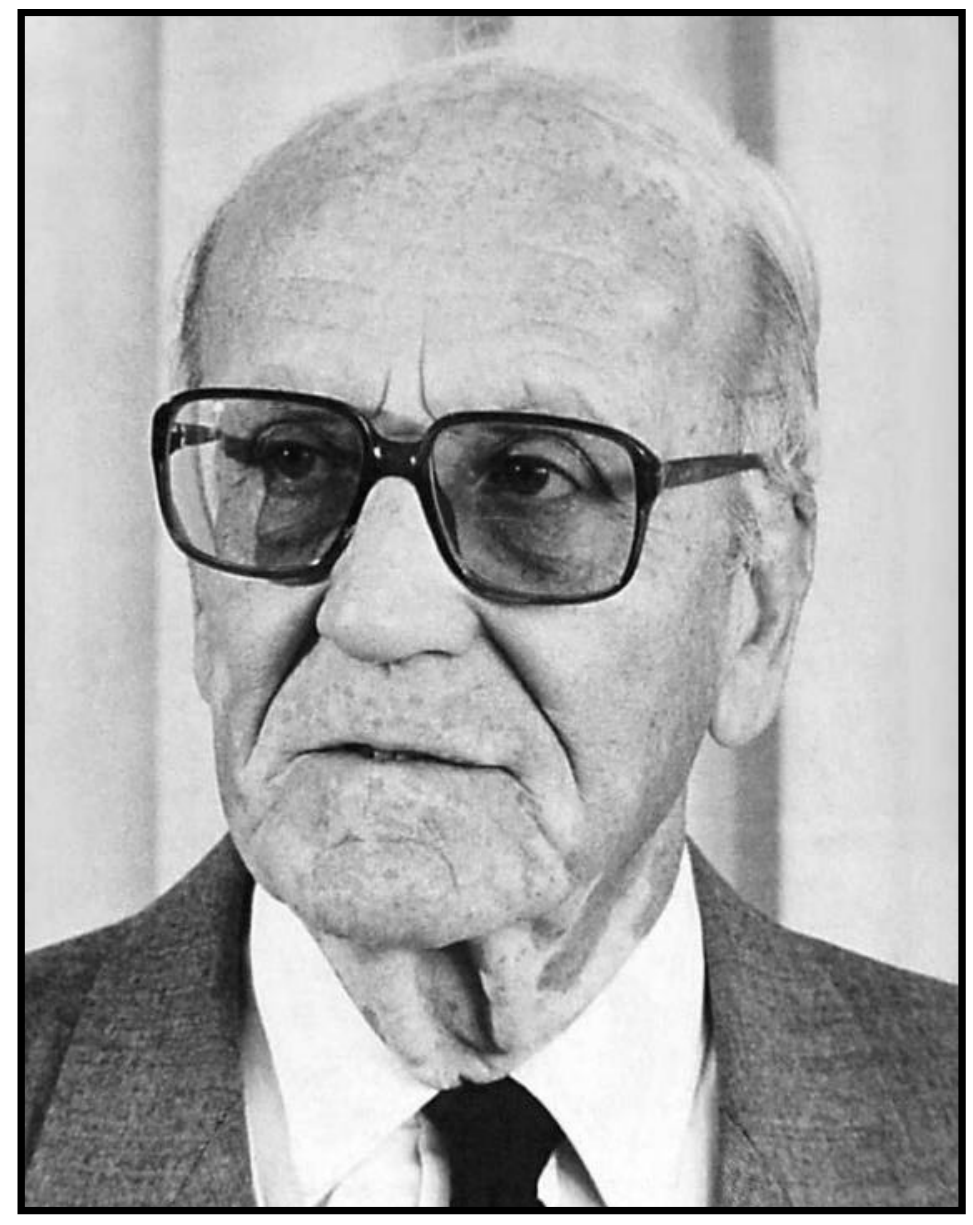


Francia, en donde fue invitado por don Salvador Zubirán para viajar a México. Así llegó a México el joven catedrático, como parte del exilio español, gracias a la generosa iniciativa solidaria del gobierno del general Lázaro Cárdenas.

Como hombre de ciencia y profesor universitario, en México dirigió unas 200 tesis de licenciatura, maestría y doctorado, es autor de alrededor de un centenar de artículos científicos basados en trabajos de investigación experimental, publicados en revistas especializadas, nacionales y extranjeras, sobre temas como fitoquímica, esteroides, medicamentos antipalúdicos, vitaminas, química de grasas animales y vegetales, química de insectos, entre otros. Publicó, adicionalmente, unos 200 artículos y folletos de difusión, discusión y divulgación sobre la enseñanza de la química, productos naturales, alimentos e historia de la química y la farmacia. Es así mismo, autor de más de una docena de libros y traductor de textos que, por su importancia, se han convertido en clásicos.

Como todo gran maestro, nos dejó una pléyade de alumnos, como Yoloxóchitl Bustamante, Ángela Sotelo, Lydia Rodríguez-Hahn, Ofelia Espejo, Alfredo Büttenkleper, Ana Luisa Anaya, Silvia del Amo, María Teresa Reguero, Marisela Plascencia, Pedro Castañeda y Juan Senosiain, entre otros mexicanos, y entre los extranjeros al chileno Mario Silva, al cubano Francisco Coll, y a los colombianos Jairo Calle y Rosabel Segura. Porqué no mencionar que también ayudó a forjar a sus hijos, José, Adela y Carmen como profesionales destacados de la ingeniería química, él, y la farmacia, ellas. Una de las últimas tesis que dirigió, quizás la última, fue la de Ángela López Giral, su nieta, quien recibió su influencia para realizar un doctorado en química orgánica-productos naturales.

Son innumerables las distinciones que recibió durante su desempeño académico y profesional. Destacan entre ellas el nombramiento como profesor emérito de la UNAM; los doctorados honoris causa por las Universidades Nacional de México, La Habana, Lima, Caracas y Sao Paulo; los premios nacionales "Leopoldo Río de la Loza" en ciencias farmacéuticas, "Andrés Manuel del Río" de la Sociedad Química de México, y "Martín de la Cruz" del sector salud; las membresías correspondientes de la Academia de Ciencias Farmacéuticas de México, de la Academia de Ciencias Exactas Físicas y Naturales de la República Argentina, de la Sociedad Química del Perú y de la Asociación de Química y Farmacia del Uruguay. Asímismo, se desempeñó como asesor de la Organización de las Naciones Unidas para la Educación, la Ciencia y la Cultura (UNESCO) y de la Organización Mundial de la Salud (OMS).

El doctor Giral, maestro extraordinario, humanista de excepción y universitario por vocación, promovió y realizó con impecable coordinación los distintos aspectos de la misión universitaria, que son las tres características de la actitud del hombre ante el conocimiento universal: la adquisición (investigación), la transmisión (enseñanza) y la aplicación (utilización) de ese conocimiento.

En 1980, a su regreso a Salamanca donde, después de la muerte de Francisco Franco, retoma por un corto tiempo su cátedra del departamento de química orgánica en la Facultad de Farmacia, Giral se refiere al papel de los universitarios frente a los retos de un país: "como universitario del exilio pienso hoy que un Estado moderno, una nación de vanguardia - aunque ya no alcance la posición de soberana del mundoes hoy el fruto de la iluminación y la dirección de sus graduados de estudios superiores, sustancialmente los titulados universitarios, no sólo en su aspecto docente como formador de profesionales sino también - y ante todo- en su aspecto rector del pensamiento libre, del juicio crítico político-social y de la investigación científica. Soy partidario de aceptar la responsabilidad ante la nación entera del desarrollo del país y pienso que los universitarios debiéramos asumir el compromiso de defender y mantener la calidad, la intensidad y la continuidad de la vida universitaria como la mejor forma de contribuir al progreso espiritual y material de España, independientemente de su organización política y de su tendencia social."

Otra frase notable de don Francisco Giral llama la atención porque no expresa resentimiento alguno por haber perdido la guerra y su trabajo en su país natal, quizás porque logró cumplir con su tarea de universitario cabal en otro país, México: "Acaso, en aquella aurora de esperanzas que empezaba a brillar en 1936 se nubló el alba de un nuevo siglo de oro español. Los universitarios del exilio no deseamos reclamar nada con violencia material ni con violencia espiritual, seguiremos clamando con esclarecida dialéctica, sin agresiones, con tolerancia recíproca, por la firmeza de nuestras ideas en torno a la formación de mejores universitarios, de mejores ciudadanos dotados de voluntades firmes, inteligencias claras y corazones nobles" [3].

Y cerramos como iniciamos, con palabras de Jaime Kravzov [1]: "Sus alumnos reconocemos que el doctor Giral, además de sus enseñanzas farmacéuticas, nos supo inculcar el amor a la ciencia, el compromiso con la verdad, una ética inquebrantable frente a nuestra disciplina y el deber ineludible de luchar por un mundo más justo para todos". El maestro Giral ya no está con nosotros, ahora acompaña en nuestro recuerdo a su querida esposa, colega de profesión, testigo entusiasta de su presencia internacional, colaboradora lúcida y desinteresada en su proyecto de vida, doña Petra Barnés. Descansen en paz.

\section{Referencias}

1. Kravzov, J., Francisco Giral González. En Nuestros Maestros, tomo I, págs. 97-100, Edición de la UNAM, México, 1996.

2. Giral, F. Teoría y práctica de la enseñanza de la química, en Seminario de teoría de la ciencia, Miguel A. Quintanilla (editor), Ediciones Universidad de Salamanca, págs. 177-201, Salamanca, 1982.

3. Giral, F. Comentarios químico-farmacéuticos a la historia española en América, Ediciones Universidad de Salamanca, Salamanca, 1980, 101 págs. 